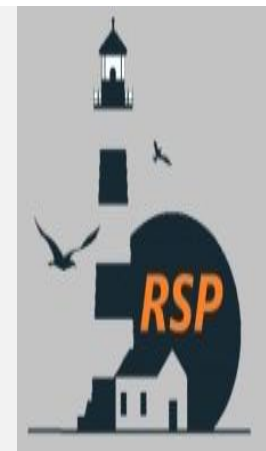

INTERNATIONAL RESEARCH JOURNAL ON ADVANCED SCIENCE HUB (IRJASH)

e-ISSN: 2582-4376

Open Access

Available online at www.rspsciencehub.com

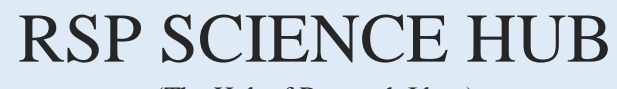

(The Hub of Research Ideas)

\title{
Performance and emission analysis in four stroke diesel engine using biodiesel blends as fuel
}

U. Karthick ${ }^{1}$, T.Venkatajalapathi ${ }^{2}$, A.VimalKodeeswaran ${ }^{3}$, P.Ashok Kumar ${ }^{4}$

${ }^{1,3}$ Assistant Professor, Department of Mechanical Engineering, SNS College of Technology, Coimbatore, Tamilnadu, India.

${ }^{2}$ Associate Professor, Department of Mechanical Engineering, SNS College of Technology, Coimbatore, Tamilnadu, India.

${ }^{4}$ Assistant Professor, Department of Mechanical Engineering, Dr.N.G.P. Institute of Technology Coimbatore, Tamil Nadu, India.

1ukarthick17@gmail.com

\section{Abstract}

In the present world it is essential to find an alternate fuel source due to the increased industrialization a depletion in natural resources. The method of obtaining biodiesel from various sources and blending them $w$ diesel is adopted in many economically developed and developing countries around the world. This pat investigates the utilization of Pongamia Pinnata Methyl Ester (PPME) blends with diesel in CI engine. 1 performance and emission characteristics of pongamia with diesel with $B 40$ could substitute in the place pure diesel and be used as an alternate source of fuel in the near future, thus saving the natural resources; the future generation. Performance parameter like brake thermal efficiency, specific fuel consumptic mechanical efficiency, brake power is evaluated.

\section{Key words: Biodiesel, Pongamia Pinnata Methyl Ester (PPME), CI engine.}

\section{INTRODUCTION}

An ever increasing demand of fuels has been a challenge for today's scientific workers. The fossil fuel resources are dwindling day with the aid of day. Biodiesel seem to be a solution for future. Using straight vegetable oil in diesel engines is not a new idea. Dr. Rudolf Diesel first used peanut oil for demonstration of his newly developed compression ignition (CI) engine in year 1910. Later with the availability of inexpensive petroleum, crude oil fractions have been sophisticated to serves as 'diesel', a gas for CI engines.[1-4] During the period of world war-II, vegetable oils were again used as fuel in emergency situations when fuel availability became scarce. Now days, due to limited resources of fossil fuels, rising crude oil prices and increasing worries for environment, there has been renewed focal point on vegetable oil and animal fat as alternative to petroleum fuels. In India only non-safe to eat oil can be used as a raw cloth for biodiesel production. Due to stress on safe to eat oils like groundnut, rapeseed, mustard and soybean etc. non-edible oil of jatropha curcas and karanja (Pongamia Pinnata) are evaluated as diesel fuel extender. In IC engine, the thermal strength is released by means of burning the gasoline in the engine cylinder. The combustion of gas in IC engine is quite quick but the time wanted to get a acceptable air/fuel mixture relies upon in the main on the nature of fuel and the approach of its introduction into the combustion 
chamber. [5-9] The combustion system in the cylinder ought to take as little time as possible with the release of most heat electricity in the course of the duration of operation. Longer operation results in the formation of deposits which in mixture with other combustion products may additionally cause immoderate put on and corrosion of cylinder, piston and piston rings. two The combustion product should not be poisonous when exhausted to the atmosphere. These necessities can be blissful the use of a variety of liquid and gaseous fuels. The biodiesel from nonfit for human consumption sources like Jatropha, Pongamia, Mahua, Neem and so on meets the above engine performance requirement and consequently can offer perfect doable choice to diesel oil in India P.K. Sahoo et al [10,11]. The experiment on the diesel engine are performed and discovered out that it increase the BSFC the use of a number blends of biodiesel from a range of sources including diesel Dwivedi et al [5]. The finding suggests that there is increase in the BSFC when the usage of biodiesel as in contrast to diesel for the equal strength output. This is because that the heating value of biodiesel is less as compared to diesel. It is found that there is no significant change in the thermal efficiency while using biodiesel up to B20 but there is a slight decrease in thermal efficiency when B100 was used which is due to the lower energy content of biodiesel

\section{H.A. PHADTARE et al [4].}

\section{EXPERIMENTAL METHODOLOGY}

\subsection{Setup}

The experimental set-up is illustrated in Fig. 1, which is a single cylinder four stroke, naturally aspirated direct injection and water cooled diesel engine. The specifications of the test engine are given in Table 1.

Table.1. Specification of Diesel Engine

\begin{tabular}{|l|c|}
\hline Make & Kirloskar \\
\hline Rated Brake Power & $5 \mathrm{Hp}$ \\
\hline Rated Speed & $1500 \mathrm{rpm}$ \\
\hline Number of Cylinder & One \\
\hline Bore & $80 \mathrm{~mm}$ \\
\hline Stroke & $110 \mathrm{~mm}$ \\
\hline Cooling System & Water \\
\hline Starting & Manual \\
\hline Compression ratio & 16.5 \\
\hline
\end{tabular}

\subsection{Fuel Properties}

The fuel properties were determined and are listed in Table 2, for diesel, Pongamia biodiesel, B40 and B40 with EHN. Properties of fuel shown in table 2.

\section{Table.2. Properties of fuel}

\begin{tabular}{|l|l|l|l|l|}
\hline Property & Diesel & pongamia & B40 & B40E1 \\
\hline $\begin{array}{l}\text { Density } \\
(\mathrm{g} / \mathrm{cc})\end{array}$ & 0.832 & 0.874 & 0.840 & 834 \\
\hline $\mathrm{CV}(\mathrm{kJ} / \mathrm{kg})$ & 44000 & 29,442 & 37,490 & 51324 \\
\hline Flash Point $\left({ }^{\circ} \mathrm{C}\right)$ & 60 & 156 & 89 & - \\
\hline $\begin{array}{l}\text { Kinematic Viscosity } \\
(\mathrm{Cst}) \text { @ 30 }\end{array}$ & 2.5 & 19 & 11 & - \\
\hline
\end{tabular}

\subsection{Experimental Test Procedure}

The engine was allowed to reach its steady state by running it for about 10 minutes. The Experimental setup shown in Fig.1.The engine was sufficiently warmed up and stabilized before taking all readings. After the engine reached the stabilized working condition, the load applied, fuel consumption, brake power and exhaust temperature were measured. The values were recorded thrice and a mean of these was taken for comparison. The engine performance and Exhaust emissions were studied at different loads. The brake specific fuel consumption, brake specific energy consumption and thermal efficiency were calculated. The emissions such 
as $\mathrm{CO}, \mathrm{HC}$, and NOX were measured using exhaust gas analyzer. The engine is operated at constant speed of $1500 \mathrm{r} / \mathrm{min}$. The first stage of experiment is performed with pure diesel at different loads from no load to full load. The second stage of experiment is conducted using various blends of diesel - biodiesel blend of B40 and B40 with cetane improver EHN. These performance and emission characteristics for different fuels are compared with the result of baseline diesel.

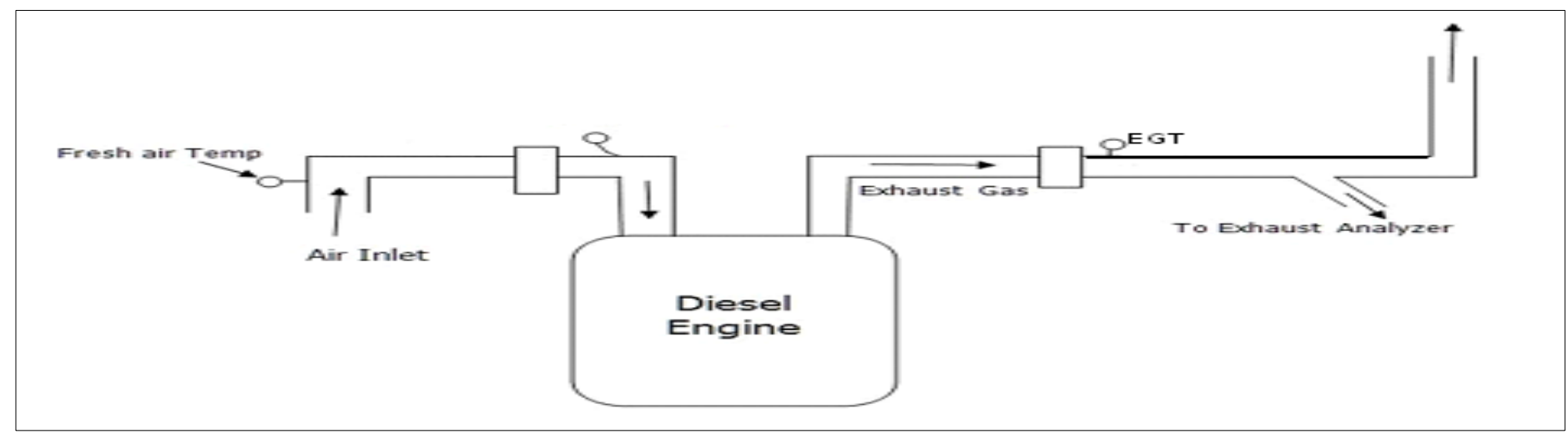

Fig.1. Experimental setup

\section{RESULTS AND DISCUSSION}

The engine was run on different loads to investigate the effect of adding cetane improver with engine performance and emissions. The performance and emission data was analyzed and presented graphically for thermal efficiency, $\mathrm{BSFC}$, exhaust gas temperature, $\mathrm{CO}, \mathrm{CO} 2, \mathrm{HC}$ and NOx emissions.

\subsection{Performance Analysis}

The results obtained from the experimental investigation using diesel and biodiesel fuel of B40 blends with EHN as cetane improver with a variation in load as $(0,2.5,5,7.5$, and 10) are presented in graphical form.

\subsubsection{Brake Thermal Efficiency}

The variation of brake thermal efficiency is shown in the Fig.2, The BTE for biodiesel blends B40, B40E1was found almost comparable to that of diesel. Perhaps due to higher cetane number and inherent presence of oxygen in the biodiesel produced better combustion. In addition the Pongamia and its blends have lower viscosity. The reduction in viscosity of Pongamia leads to improved atomization, fuel vaporization and combustion. Maximum brake thermal efficiency was obtained for diesel at full load. At full load the blend (B40) with EHN was slightly lesser than diesel. Pongamia B40 blend shows lesser BTE than diesel at all loads.

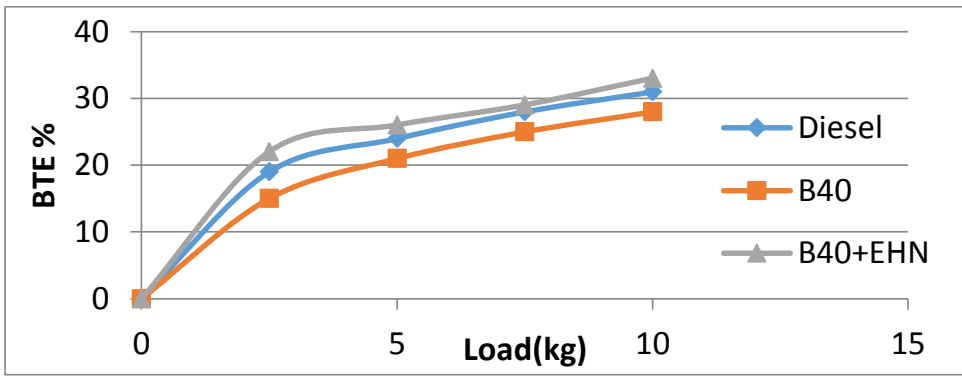

Fig.2.Effect of variation of Load on BTE

\subsubsection{Brake specific fuel consumption}

The graph reports the result of BSFC which states that as the load decreases the fuel consumption for different blends of biodiesel increases. The possible reason may be that, at lower loads, significant proportion of the fuel inducted through the intake does not burn completely due to lower quantity of pilot fuel, 
low cylinder gas temperature and lean fuel air mixture. Another reason may be that at higher load, the cylinder wall temperature is increased, which reduces the ignition delay leading to the improvement in combustion and reduction in fuel consumption. Effect of variation of Load on BSFC shown in fig.3.

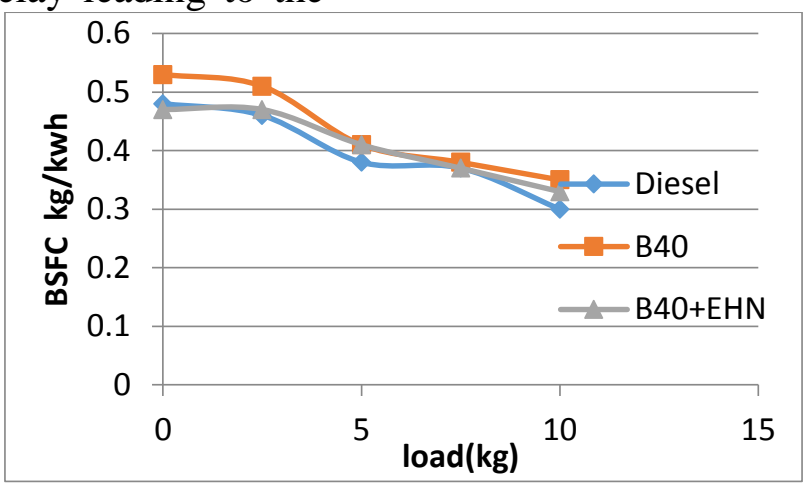

Fig.3. Effect of variation of Load on BSFC

The BSFC depends on fuel specific gravity, viscosity and calorific value. The specific gravity increases and calorific value decreases and more amount of fuel is needed to produce the same amount of energy. As the Pongamia biodiesel proportion in blend is increased BSFC also increase. As it is clear from the results BSFC for diesel $(580 \mathrm{~g} / \mathrm{kWh}),(661 \mathrm{~g} / \mathrm{kWh})$ for B40, (669 $\mathrm{g} / \mathrm{kWh}$ ) for B40 with EHN1 respectively 13.5and $14.9 \%$ respectively higher than diesel the increase in brake specific fuel consumption with increase in concentration of blends in diesel fuel is attributed to lower heat values. Variation of exhaust gas temperatures with load of engine for different fuels shown in fig 4.

\subsubsection{Exhaust gas temperature}

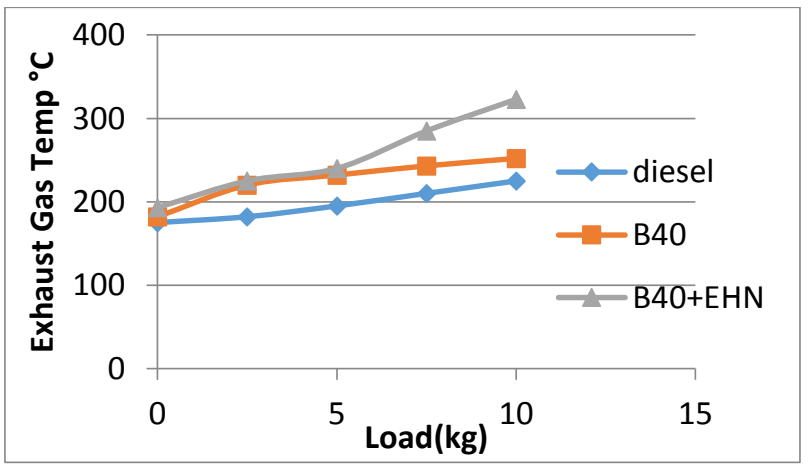

Fig.4. Variation of exhaust gas temperatures with load of engine for different fuels

Exhaust gas temperature increased with increase in load on the engine. This may be attributed to increase in quality of fuel injected with the increase in load. The increased quantity of fuel generated greater heat in combustion chamber. Maximum exhaust gas temperature of $326^{\circ} \mathrm{C}$ was obtained for pongamia B40 blend with EHN at full load. Exhaust gas temperature increased for all fuel types because of pressure rise in combustion chamber and an increase in fuel injection rate with increase in brake load.

\subsection{Exhaust emission analysis}

\subsubsection{CO emissions}

Fig. 5 displays the variation of $\mathrm{CO}$ emissions with the increase in load.It is interesting to note that the engine emits more $\mathrm{CO}$ for diesel as compared to biodiesel blends under all loading conditions. It is seen from the Fig. 5 that the CO concentration is totally absent for the blends of B40 and B40EHN for full loading condition. At lower biodiesel concentration, the oxygen present in the biodiesel aids for complete combustion. However as the biodiesel concentration increases, the negative effect due to high viscosity and small increase in specific gravity suppresses the complete combustion process, which produces small amount of CO. CO concentration in exhaust gas was $0.2,0.04$ and $0.1 \%$ at full load for diesel, pongamia B40 and B40EHN fuels respectively. 


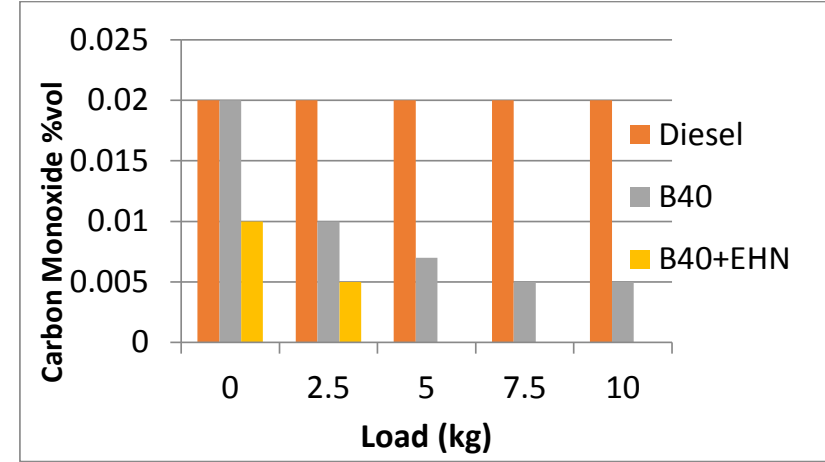

Fig. 5. Variation of CO emission with load of engine for different fuels

\subsection{2 $\mathrm{CO}_{2}$ emissions}

Fig.6 depicts the $\mathrm{CO}_{2}$ emission of various fuels used. The $\mathrm{CO} 2$ emission increased with increase in load for all blends. The lower percentage of biodiesel blends emits less amount of $\mathrm{CO} 2$ in comparison with diesel. Blends B40 and B40EHN emit very low emissions.

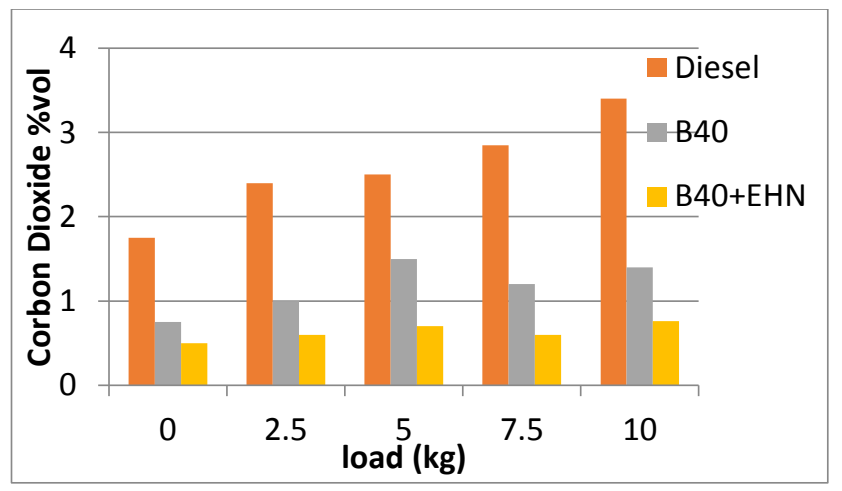

Fig.6. Variation of $\mathrm{CO}_{2}$ with respect to loads

This is because biodiesel is a low carbon fuel and has a lower ratio of elemental carbon to hydrogen compared to diesel fuel. The rise in $\mathrm{CO} 2$ emissions was observed using higher content of biodiesel blends, due to the incomplete combustion as explained earlier. Although higher biodiesel content emits $\mathrm{CO} 2$ nearly equal to diesel at higher loads, biodiesel itself is considered.

\subsubsection{HC emissions}

The HC emission variation for different blends is indicated in Fig. $7 \mathrm{HC}$ emission decreases with increase in load for diesel and it is almost nil for all biodiesel blends B40 and B40E1.

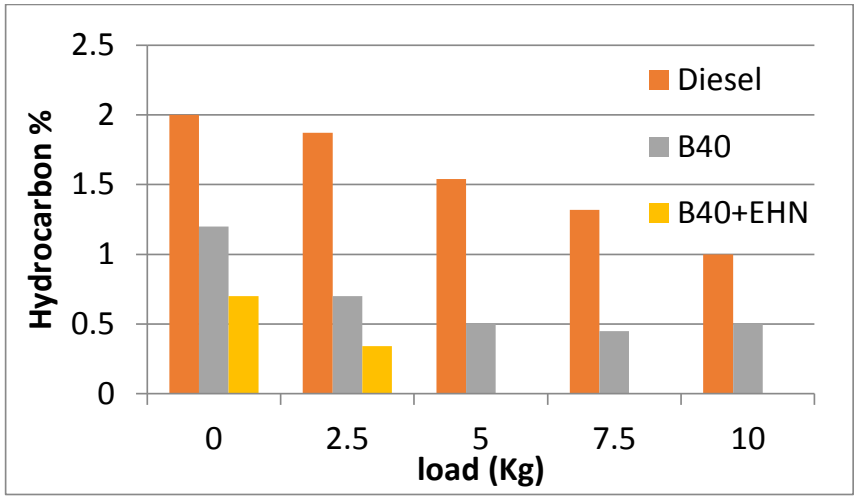

Fig. 7. Variation of Unburned HC with Loads As the Cetane number of ester based fuel is higher than diesel, it exhibits a shorter delay period and results in better combustion leading to low $\mathrm{HC}$ emission. Also the intrinsic oxygen contained by the biodiesel was responsible for the reduction in $\mathrm{HC}$ emission.

3.2.4 NOx emissions

The variation of NOx emission for different fuel blends is indicated in Fig. 8.

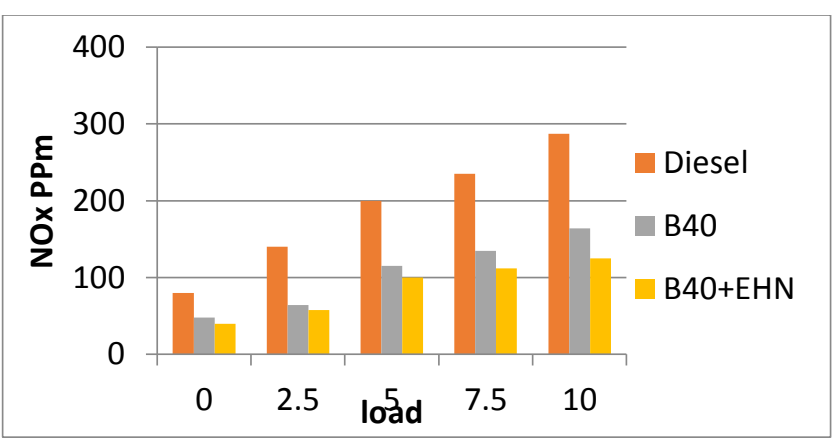

\section{Fig.8 Variation of oxides of Nitrogen with loads}

The NOx emission for diesel and all the fuel blends followed an increasing trend with respect to load. For the blends an increase in the emission was found at all loads when compared to diesel. NOx is formed generally at high temperatures. Since the exhaust gas temperatures are higher the NOx emissions are also higher. Another factor causing the increase in NOx could be the possibility of higher combustion temperatures arising from improved combustion because larger part of the combustion is completed before TDC for ester blends compared to diesel due to their lower ignition delay. So it is 
highly possible that higher peak cycle temperatures are reached for ester blends compared to diesel.By adding cetane improver with the blend B40 was found that decreasing NOx emission while compared to pongamia B40 blend.

\section{Conclusion}

Biodiesel with higher flash point, biodegradability and nontoxic nature are safe to handle, store and create lesser problems in case of accidental release or spillage and hence superior to diesel oil. Based on the above experimental investigations, it was found that blends of PPME and diesel could be successfully used in diesel engines without any modification, with acceptable performance and better emissions. Based on the engine performance, the blends B40 and B40 with EHN are comparable and better in some aspects than that of fossil diesel, and from emission point of view, blends $\mathrm{B} 40$ and $\mathrm{B} 40 \mathrm{ENH}$ are superior to diesel. Hence it is concluded that the biodiesel up to $40 \%$ (B40) could replace the diesel in diesel engine applications of transport sector, remote rural electrification for getting the expected power output with less emissions leading to energy economy and environmental protection.

Based on the engine performance and also from emission point of view, the blend B40EHN was comparable and better in some aspects than that of diesel fuel

It is clearly evident that biodiesel with several desirable characteristics would allow modern diesel engines to use biodiesel without engine modifications and without any reduction in the engine performance. Much attention should be focused on the use of biodiesel to replace fossil fuel in order to prevent environmental degradation due to fossil combustion. In the near future conventional fuels would be fully replaced by biodiesel and would provide a viable solution for the much threatening energy crisis and environmental pollution problems.

\section{References}

[1] Bobade S.N (2012) Detail study on the Properties of Pongamia Pinnata (Karanja) for the Production of Biofuel. Research Journal of Chemical Sciences Vol. 2(7), 16-20.
[2] D balajee (2013): performance and combustion characteristics of ci engine with variable compression ratio fuelled with pongamia and jatropha and its blends with diesel. International journal of mechanical engineering and robotics researchvol. 2, no. 3

[3] Ekanath R. Deore (2013): Effect of Compression Ratio on Energy and Emission erformance of Single Cylinder Diesel Engine Fueled with Jatropha and Karanja Biodiesel. International Journal of Thermodynamics(IJoT) Vol. 16 (No. 3), pp. 132-144, 2013

[4] H.A. PHADTARE (2013): combustion characteristics of $\mathrm{CI}$ engine using karanja biodiesel blends as fuel. International Journal of Engineering Science and Technology (IJEST)Vol. 5 No.05

[5] Gaurav Dwivedi (2013): Performance Evaluation of Diesel Engine Using Biodiesel from Pongamia Oil. international journal of renewable energy research Vol.3, No.2, 2013

[6] Tapan K. Gogoi (2011): Comparative Analysis of Performance and Combustion of Koroch Seed Oil and Jatropha Methyl Ester blends in a Diesel Engine. World renewable energy congress-sweden

[7] M.prabhahar (2012): performance and emission studies of a diesel engine with pongamia methyl ester at different load conditions. International journal of engineering research and applications (ijera) vol. 2, issue 3, may-jun 2012, pp.2707-2713

[8] Arun K. Vuppaladadiyam (2013): Transesterification of Pongamia pinnata Oil Using Base Catalysts: A Laboratory Scale Study. Universal Journal of Environmental Research and Technology Volume 3, Issue 1: 113-118

[9] S.R. Arote Pongamia pinnata L: A Comprehensive Review International Journal of PharmTech Research Vol.2, No.4, pp 2283-2290,

[10] K. Sureshkumar and R. Velraj (2007) Performance and Characteristics Study of the Use of Environment Friendly Pongamia Pinnata Methyl Ester in C. I. Engines. 
Journal of Energy \& Environment, Vol. 5, May 2007.

[11] P.K. Sahoo(2009): Combustion analysis of Jatropha, Karanja and Polanga based biodiesel as fuel in a diesel engine. Fuel 88 (2009) 994-999. 